\title{
PREVALENCE OF HYPOXAEMIA IN PAEDIATRIC PATIENTS ATTENDING CHILDREN OUT PATIENT CLINIC
}

\author{
Alex-Hart BA ${ }^{1}$, Yaguo Ide $\mathbf{L E}^{2} *$ \\ ${ }^{1}$ Department of Paediatrics, University of Port Harcourt Teaching Hospital, Port Harcourt, Nigeria \\ ${ }^{2}$ Department of Paediatrics, University of Port Harcourt Teaching Hospital, Port Harcourt, Nigeria
}

DOI: https://doi.org/10.15520/ijmhs.v9i12.2750

Reviewed By: Dr.

Daniel V.

Department: Medical

* Corresponding author.

Email:

lucyaguolucy@gmail.com

\section{ABSTRACT}

Background; In more developed countries, it is a common practice to use pulse oximetry for the diagnosis of hypoxaemia, regrettably, it is not so in resource limited environments like ours especially in outpatient settings while carrying out emergency triage assessment. Aim; The aim of this study was to determine the prevalence of undictated hypoxaemia among children presenting to the children outpatient clinic of the department of paediatrics at the University of Port Harcourt teaching hospital. Methods; This descriptive cross-sectional study of the prevalence of hypoxemia was conducted at the children outpatient clinic of the department of paediatrics at the University of Port Harcourt teaching hospital. The room air oxygen saturations of paediatric outpatients were measured at rest from May, 2019 to September, 2019 using digital pulse oximetry. Hypoxaemia was defined as $\mathrm{SpO} 2$ less than $90 \%$ in room air at rest. Results; A total of 351 children were recruited for the study of which $201(57.3 \%)$ were males and $150(42.7 \%)$ were females giving a Male: Female ratio of $1.34: 1,233(66.38 \%)$ were under-fives. Prevalence of hypoxaemia was $40(11.4 \%)$. Acute respiratory infection (ARI) was the commonest condition presenting to the children outpatient clinic in 119(33.9\%) and it was also the condition with the highest prevalence of hypoxia 11 $(27.5 \%)$ of all the cases with hypoxia followed by malaria $4(10 \%)$ and diarrhoea $4(10 \%) \quad$ Oximetry finding enabled patient to be seen faster ( accelerating triaging) and sent to the children emergency room for oxygen therapy amidst other treatments. In conclusions, there is a high prevalence of hypoxemia among children presenting at the outpatient clinic of the department of paediatrics at the University of Port Harcourt teaching hospital. There should be routine screening for hypoxaemia during emergency triage and assessment by the outpatient clinic nurses. Pulse oximeter should be made available to the outpatient clinic nurses by the hospital to enable them routinely screen for hypoxaemia and prioritize the patients with hypoxaemia among patients to be quickly seen by paediatricians and oxygen therapy commenced to reduce morbidity and mortality from hypoxaemia. Key words: Hypoxia Paediatrics Prevalence Children Pulse Oximetry Oxygen 


\section{INTRODUCTION}

In spite of the current solid effort worldwide, death rates have remained high in children, particularly in underdeveloped countries Black [1] One very common problem that follows curable lethal childhood illnesses is hypoxaemia. Subhi [2] and Emergency triage assessment and treatment (ETAT) and WHO Integrated Management of childhood illness(IMCI) guiding principles stresses the importance of treating hypoxaemia with oxygen.WHO[3,4] In children with pneumonia hypoxia is a prognostic factor of severe disease and has been shown to be a danger sign for mortality. Duke [5]. There is no reservation that finding of hypoxia presents a task in resource inadequate situations like ours. Pulse oximetry is critical to the accurate detection of hypoxaemia for which prompt treatment can be initiated with oxygen. Weber [6]

Pulse oximetry is an automation that enables one make a diagnosis of hypoxaemia in developed nations. Mcmorrow [7] It has been demonstrated to be more efficacious than clinical verdict in the recognition of hypoxaemia. Moller [8] and is recognized in high in-come countries as the $5^{\text {th }}$ vital sign. Mower,Mower[9,10] Studies in Papua New Guinea have demonstrated that use of Pulse Oximeters and oxygen concentrators in children with pneumonia can reduce mortality when accompanied by training on their use.Matai, Duke[11,12] In hospitals in Kenya, use of pulse oximeters in emergency triage assessment has encouraged a more judicious use of oxygen therapy.Maniki[13] There is a dearth of literature on the use of pulse oximeter in out patient clinics in developing countries and the prevalence of hypoxaemia, whereas the reverse is the case in developed countries, as illustrated by the reduction in paediatric emergency unit duration of state in the united states when pulse oximeter is used for patient triage, accelerating the recognition and management of patients with
hypoxaemia.Choi[14] Few studies have reported the prevalence of hypoxaemia in developing countries and most have been on pneumonia[2] and in children at the emergency room. Okoh[15] Other workers have reported higher prevalence of hypoxaemia amongst children with neonatal illnesses, anaemia, malaria, tuberculosis, diarrhoea, malaria malnutrition and meningitis. Wandi, Junge, Maitland [16,17,18]. To the best of our knowledge non has reported the prevalence of hypoxaemia at outpatient clinic. The aim of this study therefore is to determine the prevalence of hypoxaemia amongst children who present with their parents or caregivers to the children out patient clinic of the University of Port Harcourt teaching hospital so as to accelerate their being seen and oxygen therapy commenced.

\section{MATERIALS AND METHODS}

A descriptive cross-sectional study was conducted to determine the prevalence of hypoxemia among children who presented to the children outpatient clinic of the department of paediatrics at the University of Port Harcourt teaching hospital with their parents or caregivers. The study was conducted over a 4-months period may 2019 to September 2019. The University of Port Harcourt teaching hospital is a tertiary hospital in the Southern part of Nigeria. The outpatient clinic of the University of Port Harcourt teaching hospital does not own pulse oximeter, however the individual residents and the consultants including the researchers were able to procure pulse oximeters to enhance their clinical practice. Opportunistic sampling method was used. All children above one month of age who presented to the outpatient clinic where consecutively enrolled if their parent or caregivers consented to the study. Inpatients did not meet the criteria for the study. 400 structured 
questionnaires were administered to retrieve information on patients name, age, sex, diagnosis, oxygen saturation reading, however only 351 were properly documented and returned. Written informed consent was obtained from the patient or caregivers, a digital pulse oximeter ( Measupro Inc, model number 0x250) was then used to measure the oxygen saturation by placing the pulse oximeter on the index finger and allowing the signal to equilibrate for a few seconds. When the waveform was high quality and the oxygen saturation reading became stable the level was recorded. Measurements were obtained at rest in room air. The oxygen saturation level of the paediatrician obtaining the measurements was taken to serve as control and confirm that the digital pulse oximeter was functioning appropriately. All measurements were obtained by researcher and assigned resident doctors enrolled to assist with data collection. For the purpose of this study hypoxia was defined as oxygen saturation less than $90 \%$. Data was collected from Monday through Friday as the outpatient clinic is closed during weekends and children are meant to be seen in the emergency room at weekends. Data was collected until desired sample size was met, and entered into an excel spread sheet, analysed using statistical package for social sciences version 20.

The sample size was determined using Fisher's formula for sample size determination:

$$
\begin{aligned}
& \mathrm{n}=\frac{\mathrm{z}^{2} \mathrm{p}(1-\mathrm{p})}{\mathrm{d}^{2}} \\
& \mathrm{n}=\text { sample size } \\
& \mathrm{z}=\text { confidence interval }(95 \%)=1.96 \\
& \mathrm{p}=41.5 \%=0.415 \text { Ibrahim }[19] . \\
& \mathrm{d}=\text { study precision }(\text { taken as } 5 \%=0.05) \\
& \mathrm{n}=\frac{1.96^{2} \times 0.415 \times(1-0.415)}{0.05^{2}}=373
\end{aligned}
$$

\section{RESULTS}

Three hundred and fifty-one mother- child pair were recruited for the study. The mean age of the children was $52.03 \pm 50.345$ months. Their age category showed that $233(66.38 \%)$ were aged less than 60 months and $116(33.05 \%)$ were above 60 months of age and $2(0.57 \%)$ had no recorded age. There were $201(57.3 \%)$ males and $150(42.7 \%)$ females with male to female ratio of 1.3: 1. Table 1 shows the diagnosis of the patients. The commonest diagnosis was Acute respiratory infection 129 (36.8\%), followed by Malaria $48(13.7 \%)$. seizure disorder $18(5.1 \%)$ and diarrhoea 17 (4.8\%).

Forty (11.4\%) patients were hypoxic, while 311 $(88.6 \%)$ were not. Table 2 showed the relationship between age group and gender of the patients with the prevalence of hypoxia. Out of the $40(11.4 \%)$ hypoxic patients, $32(80 \%)$ were less than 60 months of age. This was not statistically significant $\left(\chi^{2}=3.801, \mathrm{p}=0.051\right)$. Out of the $40(11.4 \%)$ patients with hypoxia, 23 $(57.5 \%)$ were males and $17(42.5 \%)$ were females. This difference in observation was not statistically significant $\left(\chi^{2}=001, p=.958\right)$.

Table 3 shows the association between patients' diagnosis and prevalence of hypoxia. Majority of those with hypoxia had acute respiratory infection $11(27.5 \%)$. This is followed by those with malaria $4(10.0 \%)$ and diarrhoea $4(10.0 \%)$. This difference in observation is not statistically significant $\left(\chi^{2}=41.946, p=0.970\right)$. 
November 2019. Table 1: Patients' diagnosis

\begin{tabular}{|c|c|c|}
\hline DIAGNOSIS & FREQUENCY & PERCENTAGE \\
\hline Acute respiratory infection & 129 & 36.8 \\
\hline Malaria & 48 & 13.7 \\
\hline Seizure disorder & 18 & 5.1 \\
\hline Diarrhoea & 17 & 4.8 \\
\hline Congenital heart disease & 12 & 3.4 \\
\hline Stomach ulcer & 11 & 3.1 \\
\hline Dermatitis & 10 & 2.8 \\
\hline Gynaecomastia & 7 & 2.0 \\
\hline Sickle cell anaemia & 7 & 2.0 \\
\hline Medical checkup & 7 & 2.0 \\
\hline Dactylitis & 5 & 1.4 \\
\hline Vaginal candidiasis & 5 & 1.4 \\
\hline Asthma & 4 & 1.1 \\
\hline Fracture & 4 & 1.1 \\
\hline Haemorrhoids & 4 & 1.1 \\
\hline Hearing loss & 4 & 1.1 \\
\hline Hydrocele & 4 & 1.1 \\
\hline Spinal bifida & 4 & 1.1 \\
\hline Wax impaction & 4 & 1.1 \\
\hline HIV exposed & 3 & 0.9 \\
\hline Hypoglycaemia & 3 & 0.9 \\
\hline Urinary tract infection & 3 & 0.9 \\
\hline Impaired speech & 3 & 0.9 \\
\hline Developmental delays & 2 & 0.6 \\
\hline Impetigo & 2 & 0.6 \\
\hline Lymphadenopathy & 2 & 0.6 \\
\hline Malnutrition & 2 & 0.6 \\
\hline Oral mass & 2 & 0.6 \\
\hline Sepsis & 2 & 0.6 \\
\hline Down syndrome & 2 & 0.6 \\
\hline Hernia & 2 & 0.6 \\
\hline Kyphoscoliosis & 2 & 0.6 \\
\hline Abdominal pain & 1 & 0.3 \\
\hline Burns & 1 & 0.3 \\
\hline Chest pain & 1 & 0.3 \\
\hline Enuresis & 1 & 0.3 \\
\hline Genu valrus & 1 & 0.3 \\
\hline Hirschsprungs disease & 1 & 0.3 \\
\hline Hydrocephalus & 1 & 0.3 \\
\hline Tumour & 1 & 0.3 \\
\hline Measles & 1 & 0.3 \\
\hline Migraine & 1 & 0.3 \\
\hline Neck swelling & 1 & 0.3 \\
\hline Nephrotic syndrome & 1 & 0.3 \\
\hline Osteomyelitis & 1 & 0.3 \\
\hline Poliomyelitis & 1 & 0.3 \\
\hline Polyuria & 1 & 0.3 \\
\hline AIDS & 1 & 0.3 \\
\hline Scabies & 1 & 0.3 \\
\hline Total & 351 & 100 \\
\hline
\end{tabular}


Table 2: Relationship between age group, gender and the prevalence of hypoxia.

\begin{tabular}{|l|l|l|l|l|l|}
\hline AGE GROUP & \multicolumn{2}{|c|}{ Hypoxia (\%) } & Total (\%) & Chi-square & p-value \\
\hline \multicolumn{1}{|c|}{ NO } & YES & & & \\
\hline$>60$ & $32(80)$ & $200(64.5)$ & $232(66.1)$ & & \\
\hline Total & $8(20)$ & $110(35.5)$ & $118(33.6)$ & 3.801 & 0.051 \\
\hline GENDER & $40(100)$ & $310(100)$ & $350(99.7)$ & & \\
\hline Male & & & & & \\
\hline Female & $23(57.5)$ & $178(57.2)$ & $201(57.3)$ & & .975 \\
\hline Total & $17(42.5)$ & $133(42.8)$ & $150(42.7)$ & 001 & \\
\hline
\end{tabular}

There was one with a missing age $(0.3 \%)$

Table 3: Association between patients' diagnosis and prevalence of hypoxia

\begin{tabular}{|c|c|c|c|c|c|c|}
\hline DIAGNOSIS & \begin{tabular}{|l|} 
HYPOXI \\
\end{tabular} & $(\%)$ & TOT & $\mathbf{A L}$ & CHI-square & p-value \\
\hline & YES & NO & $(\%$ & & & \\
\hline Acute respiratory infection & $11(27.5)$ & $118 \quad(37.9)$ & 129 & $(36.8)$ & & \\
\hline Malaria & $4(10.0)$ & $44 \quad(14.1)$ & 48 & $(13.7)$ & & \\
\hline Seizure disorder & $1 \quad(2.5)$ & $17 \quad(5.5)$ & 18 & $(5.1)$ & & \\
\hline Diarrhoea & $4(10.0)$ & $13 \quad(4.2)$ & 17 & $(4.8)$ & & \\
\hline Congenital heart disease & $3(7.5)$ & $(2.9)$ & 12 & (3.4) & & \\
\hline Stomach ulcer & $2(5.0)$ & $(2.9)$ & 11 & $(3.1)$ & & \\
\hline Dermatitis & $3 \quad(7.5)$ & $(2.3)$ & 10 & $(2.8)$ & & \\
\hline Gynaecomastia & $1 \quad(2.5)$ & $(1.9)$ & 7 & $(2.0)$ & & \\
\hline Sickle cell anaemia & $\begin{array}{ll}1 & (2.5) \\
\end{array}$ & $(1.9)$ & 7 & $(2.0)$ & & \\
\hline Medical checkup & $1 \quad(2.5)$ & $(1.9)$ & 7 & $(2.0)$ & & \\
\hline Dactylitis & $1 \quad(2.5)$ & $(1.3)$ & 5 & $(1.4)$ & & \\
\hline Vaginal candidiasis & $1 \quad(2.5)$ & $(1.3)$ & 5 & $(1.4)$ & & \\
\hline Asthma & $\begin{array}{ll}0 & (0.0) \\
\end{array}$ & $(1.3)$ & 4 & $(1.1)$ & & \\
\hline Fracture & $\begin{array}{ll}0 & (0.0) \\
\end{array}$ & $(1.3)$ & 4 & $(1.1)$ & 41.946 & .970 \\
\hline Haemorrhoids & $2 \quad(5.0)$ & $(0.6)$ & 4 & $(1.1)$ & & \\
\hline Hearing loss & $\begin{array}{ll}1 & (2.5) \\
\end{array}$ & $(1.0)$ & 4 & $(1.1)$ & & \\
\hline Hydrocele & $\begin{array}{|ll|}0 & (0.0) \\
\end{array}$ & $(1.3)$ & 4 & $(1.1)$ & & \\
\hline Spinal bifida & $1 \quad(2.5)$ & $(1.0)$ & 4 & $(1.1)$ & & \\
\hline Wax impaction & $\begin{array}{ll}0 & (0.0) \\
\end{array}$ & $(1.3)$ & 4 & $(1.1)$ & & \\
\hline HIV exposed & $0 \quad(0.0)$ & $(1.0)$ & 3 & $(0.9)$ & & \\
\hline Hypoglycaemia & $\begin{array}{ll}0 & (0.0) \\
\end{array}$ & $(1.0)$ & 3 & $(0.9)$ & & \\
\hline Urinary tract infection & $1 \quad(2.5)$ & $(0.6)$ & 3 & $(0.9)$ & & \\
\hline Impaired speech & $\begin{array}{ll}0 & (0.0) \\
\end{array}$ & $(1.0)$ & 3 & $(0.9)$ & & \\
\hline Developmental delays & $0 \quad(0.0)$ & $(0.6)$ & 2 & $(0.6)$ & & \\
\hline Impetigo & $0 \quad(0.0)$ & $(0.6)$ & 2 & $(0.6)$ & & \\
\hline Lymphadenopathy & $\begin{array}{ll}0 & (0.0) \\
\end{array}$ & $(0.6)$ & 2 & $(0.6)$ & & \\
\hline Malnutrition & $\begin{array}{ll}0 & (0.0) \\
\end{array}$ & $(0.6)$ & 2 & $(0.6)$ & & \\
\hline Oral mass & $1 \quad(2.5)$ & $(0.3)$ & 2 & $(0.6)$ & & \\
\hline Sepsis & $0 \quad(0.0)$ & $(0.6)$ & 2 & $(0.6)$ & & \\
\hline Down syndrome & $0 \quad(0.0)$ & $(0.6)$ & 2 & $(0.6)$ & & \\
\hline Hernia & $0 \quad(0.0)$ & $(0.6)$ & 2 & $(0.6)$ & & \\
\hline Kyphoscoliosis & $\begin{array}{ll}0 & (0.0) \\
\end{array}$ & $(0.6)$ & 2 & $(0.6)$ & & \\
\hline Abdominal pain & $\begin{array}{ll}0 & (0.0) \\
\end{array}$ & $(0.3)$ & 1 & $(0.3)$ & & \\
\hline Burns & $\begin{array}{ll}0 & (0.0) \\
\end{array}$ & $(0.3)$ & 1 & $(0.3)$ & & \\
\hline Chest pain & $\begin{array}{ll}0 & (0.0)\end{array}$ & $(0.3)$ & 1 & $(0.3)$ & & \\
\hline Enuresis & $\begin{array}{ll}0 & (0.0)\end{array}$ & $(0.3)$ & 1 & $(0.3)$ & & \\
\hline Genu valrus & $\begin{array}{ll}0 & (0.0)\end{array}$ & $(0.3)$ & 1 & $(0.3)$ & & \\
\hline
\end{tabular}




\begin{tabular}{|l|ll|lll|ll|l|l|}
\hline Hirchsprung disease & 1 & $(2.5)$ & 0 & $(0.0)$ & 1 & $(0.3)$ & & \\
\hline Hydrocephalus & 0 & $(0.0)$ & 1 & $(0.3)$ & 1 & $(0.3)$ & & \\
\hline Tumor & 0 & $(0.0)$ & 1 & $(0.3)$ & 1 & $(0.3)$ & & \\
\hline Measles & 0 & $(0.0)$ & 1 & $(0.3)$ & 1 & $(0.3)$ & & \\
\hline Migrain & 0 & $(0.0)$ & 1 & $(0.3)$ & 1 & $(0.3)$ & & \\
\hline Neck swelling & 0 & $(0.0)$ & 1 & $(0.3)$ & 1 & $(0.3)$ & & \\
\hline Nephrotic syndrome & 0 & $(0.0)$ & 1 & $(0.3)$ & 1 & $(0.3)$ & & \\
\hline Osteomyelitis & 0 & $(0.0)$ & 1 & $(0.3)$ & 1 & $(0.3)$ & & \\
\hline Poliomyelitis & 0 & $(0.0)$ & 1 & $(0.3)$ & 1 & $(0.3)$ & & \\
\hline Polyuria & 0 & $(0.0)$ & 1 & $(0.3)$ & 1 & $(0.3)$ & & \\
\hline AIDS & 0 & $(0.0)$ & 1 & $(0.3)$ & 1 & $(0.3)$ & & \\
\hline Scabies & 0 & $(0.0)$ & 1 & $(0.3)$ & 1 & $(0.3)$ & & \\
\hline Total & $40(100)$ & 311 & $(100)$ & $351(100)$ & & \\
\hline
\end{tabular}

\section{DISCUSSION}

This study investigated the prevalence of hypoxaemia among children with different diagnosis in the children outpatient clinic in the Department of Paediatrics, University of Port Harcourt Teaching Hospital. The overall prevalence of hypoxia in this study was $11.4 \%$, which is slightly higher than the $8 \%$ reported by Foran [20] among patients on admission in a district hospital in Zambia, though their sample population consisted of children and adults, while ours consisted of only children. It was also higher than the $5.3 \%$ prevalence of hypoxaemia reported by McCollum among hospitalized Malawian children under 15 years of age. McCollum [21] It was however much lower than the 59\% and 38.1\%reported in Kenya, Onyango [22] and Basnet in Nepal Basnet [23] respectively, though both studies were done among under-fives on admissions for lower respiratory infections, while our study involved children with different diagnosis, including respiratory tract infections. It is possible that the high prevalence of hypoxaemia recorded in these previous studies maybe related to the fact that only severe pneumonia cases already on admission were included in the studies, while ours included all cases seen in the outpatient clinic.

We observed that hypoxaemia was more in the younger age group compared to the older age group, though this was not statistically significant $(\mathrm{p}=0.051)$. Other researchers such as McCollum [21], Basnet [23], Salah [24] and Kuti [25] had similar observations and de Graaff also reported that the incidence of intraoperative hypoxaemia increased with younger age, with the highest incidence in neonates. De Graaff [26]

The study also revealed a slight male preponderance in the prevalence of hypoxaemia, contrasting with the study of Kuti [25] which showed a slight female preponderance. However, in both studies these findings were not statistically significant, showing that gender really had no role in the prevalence of hypoxaemia in sick children.

In this study, hypoxaemia was found among many patients with a variety of diagnosis, though acute respiratory infection accounted for a majority $(27.5 \%)$ of the cases, closely followed by malaria $(10.0 \%)$ and diarrhoea $(10.0 \%)$. This was in line with the report of Foran [20] that the most common diagnosis among the patients with hypoxaemia was respiratory infections. Acute respiratory tract infection, especially pneumonia is a very serious disease in children because it is one of the major killers of children under five years of age. Prompt recognition of hypoxaemia followed by immediate administration of supplemental oxygen will improve survival from severe pneumonia. [27,28] Several studies [2325 ] have documented hypoxaemia among 
patients with respiratory infections and others[2] like ours have also documented hypoxaemia among patients with non-respiratory diagnosis.

Interestingly, the three major diagnosis associated with hypoxaemia in this study are the three major causes of under-five morbidity and mortality.[29] The fact that hypoxaemia complicates acute diseases such as diarrhoea and malaria highlight the need for accurate diagnosis of hypoxaemia with Pulse Oximeter and it also highlights the need for an integrated approach to providing oxygen to ill children on admission to improve treatment outcome.

Conclusion, hypoxaemia is a very common complications of both childhood respiratory and non-respiratory diseases, though it is much more common with acute respiratory infections. Early diagnosis with Pulse Oximeter and prompt commencement of oxygen therapy will improve treatment outcome.

\section{REFERENCES}

1. Black RE, Cousens S, Johnson HL, et al. Global, regional, and national causes of child mortality in 2008: a systematic analysis. Lancet. 375 (2010)1969-87. [PubMed: 20466419]

2. Subhi R, Adamson M, Campbell H, et al. The prevalence of hypoxaemia among ill children in developing countries: a systematic review. Lancet Infect Dis. 92(2009)219-27. [PubMed: 19324294]

3. WHO. Integrated Management of Childhood Illness (IMCI): Management of a Child With Serious Infection or Severe Malnutrition. Geneva: World Health Organization; 2000. WHO/FCH/ $\mathrm{CAH} / 00.1$

4. WHO. Emergency Triage Assessment and Treatment (ETAT): Manual for Participants. Geneva: World Health Organization; 2005.
5. Duke T, Frank D, Mjone J, Hypoxaemia in children with pneumonia in Paupa New guinea, Int. J. Tuberc. Dis. 5(2000)511-519

6. Weber MW, Mulholland EK. Pulse oximetry in developing countries. Lancet. 351(1998)1589. [PubMed: 10326572]

7. McMorrow RC, Mythen MG Pulse oximetry. Curr Opin Crit Care 12(3) (2006)269-271

8. Moller JT, Pedersen T, Rasmussen LS et al Randomized evaluation of pulse oximetry in 20,802 patients: I. Design, demography, pulse oximetry failure rate, and overall complication rate. Anesthesiology 78(3) (1993)436-444

9. Mower WR, Myers G, Nicklin EL, Kearin KT, Baraff LJ, Sachs C Pulse oximetry as a fifth vital sign in emergency geriatric assessment. Acad Emerg Med 5(9)(1998) 858-865

10. Mower WR, Sachs C, Nicklin EL, Baraff LJ Pulse oximetry as a fifth pediatric vital sign. Pediatrics 99(5) (1997)681686

11. Matai S, Peel D, Wandi F, Jonathan M, Subhi $\mathrm{R}$, Duke $\mathrm{T}$ Implementing an oxygen programme in hospitals in Papua New Guinea. Ann Trop Paediatr 28(1)7(2008) 1-78

12. Duke $\mathrm{T}$, Wandi $\mathrm{F}$, Jonathan $\mathrm{M}$ et al Improved oxygen systems for childhood pneumonia: a multihospital effectiveness study in Papua New Guinea. Lancet 372(9646) (2008) 1328-1333

13. Mwaniki MK, Nokes DJ, Ignas J et al Emergency triage assessment for hypoxaemia in neonates and young children in a Kenyan hospital: an observational study. Bull World Health Organ 87(4)(2009) 263-270

14. Choi J, Claudius I Decrease in emergency department length of stay as a 
result of triage pulse oximetry. Pediatr Emerg Care 22(6) (2006) 412-414

15. Okoh B A, Jaja P,Hypoxaemia in Nigerian children presenting to CHEW of a tertiary hospital. Asian journal of Paediatric Reasearch. 2(2019)1-6

16. Wandi F, Peel D, Duke T Hypoxaemia among children in rural hospitals in Papua New Guinea: epidemiology and resource availability-a study to support a national oxygen programme. Ann Trop Paediatr 26(4) (2006) 277-284

17. Junge S, Palmer A, Greenwood BM, Kim Mulholland E, Weber MW The spectrum of hypoxaemia in children admitted to hospital in The Gambia, West Africa. Trop Med Int Health 11 (3) (2006) 367372

18. Maitland K, Levin M, English M et al Severe P. falciparum malaria in Kenyan children: evidence for hypovolaemia. QJM 96 (6) (2003) 427-434

19. Ibrahim R.M, Johnson W.B, Abdulkarim A.A Hypoxaemia in under-five Nigerian children in hospital with pneumonia. West African J Med 33(1)2014, 37-43

20. Foran M, Ahn R, Novik J, Tyer-Viola L, Chilufya K, Katamba K, Burke T. Prevalence of undiagnosed hypoxaemia in adults and children in an underresourced district in Zambia. Int J Emerg Med 3 (2010) 351-356.

21. McCollum ED, Bjornstad E, Preidis GA, Hosseinipour MC, Lufesi N. Multicenter study of hypoxaemia prevalence and quality of oxygen treatment for hospitalized Malawian children. Trans R Soc Trop Med Hyg 2013; 107 (5): 285292.

22. Onyango FE, Steinhoff MC, Wafula EM, Wariua S, Musia J, Kitonyi J. Hypoxaemia in Kenyan children with lower respiratory infection. BMJ 1993; 306: 612-615.
23. Basnet S, Adhikari RK, Gurung CK. Hypoxaemia in children with pneumonia and its clinical predictors. Indian Journal of Paediatrics 2006; 73: 777-781.

24. Salah ET, Algasim SH, Mhamoud AS, Husain NEOSA. Prevalence of hypoxaemia in under-five with pneumonia in an emergency Paediatrics hospital in Sudan. Indian J Crit Med 2015; 19 (4): 203-207.

25. Kuti BP, Adegoke SA, Ebruke BE, Howie S, Oyelami OA, Ota M. Determinants of oxygen therapy in childhood pneumonia in a resourceconstrained region. ISRN Paediatrics 2013; Article ID 435976:6. Available at http://downloads.hindawi.com/archive/20 13/435976.pdf. Accessed $10^{\text {th }}$ November 2019.

26. De Graaff JC, Bijker JB, Kappen TH, Wolfswinkel VL, Zuithoff NP, Kalkman CJ. Incidence of intraoperative hypoxaemia in children in relation to age. Anesth Analg 2013;117 (1): 169-175.

27. World Health Organisation (WHO). World Health Organisation programme for the control of acute respiratory infections. Acute respiratory infections in children: case management in small hospitals in developing countries. Geneva: WHO/ARI/90.5,1990

28. Usen S, Weber M, Mulholland K, Jaffar $\mathrm{S}$, Oparaugo A, Omosigho C, Adegbola $\mathrm{R}$, Greenwood B. Clinical predictors of hypoxaemia in Gambian children with acute lower respiratory tract infection: Prospective cohort study. BMJ 1999; 318 (7176): 86-91

29. World Health Organisation (WHO). Children: Reducing mortality. Available at https://www.who.int/news-room/factsheets/detail/children-reducing-mortality. Accessed $12^{\text {th }}$ 